\title{
The potential impact of size effects on compressive strength for the estimation of the Young's modulus of concrete
}

\author{
Chi-Cong $\mathrm{Vu}$ \\ National University of Civil Engineering (NUCE), Hanoi, Vietnam \\ congvc@nuce.edu.vn \\ Jérôme Weiss \\ Univ. Grenoble Alpes, CNRS, IRD, IFSTTAR, ISTerre, 38000 Grenoble, France \\ Olivier Plé
}

Univ. Savoie Mont Blanc, CNRS, LOCIE, 73000 Chambéry, France

David Amitrano

Univ. Grenoble Alpes, CNRS, IRD, IFSTTAR, ISTerre, 38000 Grenoble, France

\begin{abstract}
Concrete, a highly heterogeneous material, exhibits a clear size-dependence of its compressive strength. As the Young's modulus is generally assumed to be proportional to the compressive strength, this would, in principle, implies a dependence on sample size for this modulus. However, the elastic modulus is directly related to linear elastic deformation, while the compressive strength results from strongly non-linear processes due to the progressive development of damage and microcracking. In other words, the elastic modulus, a material-dependent parameter, should not depend on the sample size, unlike the compressive strength. Here we show, from an extensive experimental program including non-destructive and destructive tests carried out on 527 cylindrical concrete specimens with three different concrete mixtures and four different sizes, the sizeindependence of elastic properties of concrete regardless of the concrete mixes. This is in full contrast with the size-dependence of the compressive strength, and implies that (i) there is no direct proportionality between the elastic modulus (linear property) and the compressive strength (nonlinear property) of concrete, and (ii) the use of empirical expressions given in building codes (e.g. ACI 318-05; EN 1992) for estimating the elastic modulus from the compressive strength can lead to incorrect designs.
\end{abstract}


Keywords: size effect; static elastic modulus; dynamic elastic modulus; compressive strength; concrete.

\section{Introduction}

Compressive strength and modulus of elasticity are used as the fundamental material parameters in the design and assessment of concrete buildings [1]. While the compressive strength is used for calculating structures following the requirements of ultimate limit states, the elastic modulus is used for estimating the deformation as well as for the design of sections of structural concrete elements according to the serviceability limit state $[2,3]$. Similarly to other mechanical properties of concrete (e.g. tensile and flexural strengths), the elastic modulus is usually supposed to be tightly related to the compressive strength $[4,5]$. Many empirical predictions for estimating the elastic modulus from the compressive strength have been proposed for different types of concrete by several researchers (see reviews in [5-8]). In most concrete design codes, the modulus of elasticity is also predicted by using empirical expressions that assume a direct dependence of this modulus on compressive strength $[2,3,9,10]$. Following these expressions, an increase of the compressive strength would necessarily imply an increase of the modulus of elasticity. However, as a heterogeneous material, concrete exhibits a size-dependent behavior on the compressive strength [11-19]. Therefore, the sample size dependence of compressive strength would imply, from these empirical expressions, that the elastic modulus will depend as well on the size of the concrete sample. Nevertheless, in a composite material like concrete, the elastic properties are mainly affected by the volume fraction, the density and the elastic modulus of its two components which are the hydrated cement paste and the aggregates $[5,7]$. Hence, the elastic modulus of concrete is a material-dependent parameter and should not be affected by the sample size, unlike the compressive strength, as long as the sample volume is larger than the representative volume element (RVE) of the microstructure [20]. However, this assumption has been rarely checked, and there are inconsistencies between published datasets on this matter [21, 22]. Furthermore, to obtain a statistically significant result, a large number of mechanical tests performed on concrete specimens with different sizes and different mixtures is required. Nevertheless, such an exhaustive analysis has still not been performed until now, due to the fact that the measure of the elastic modulus and the 
compressive strength are generally time- and cost-consuming. As a result, it is difficult to make a strong and clear conclusion regarding the size effects on the Young's modulus of concrete.

On the other hand, concrete, a typical quasi-brittle material, does not display a linear stress-strain relation over the entire loading until failure, as strain softening is observed as the result of progressive damaging/microcracking [5, 19, 23]. This means that the elastic modulus, a linear property, is likely not proportional to the compressive strength (i.e. the peak stress), which is related to the non-linear behavior of concrete. Although several empirical expressions linking the compressive strength and the elastic modulus have shown a reasonable agreement with some datasets for different normal-weight concrete mixtures in different studies, these formulas failed to explain results obtained for other types of concrete and/or different strength grade [6, 24-26]. In particular, in all the previous studies of the relationship between the compressive strength and the modulus of elasticity, the influence of sample size on the compressive strength was not taken into account. This might cause severe shortcomings when estimating the Young's modulus from the compressive strength determined on small concrete samples in the laboratory. All the above observations call for a re-examination of (i) potential size effects on the elastic modulus; and (ii) the expressions of elastic modulus from the compressive strength. These two points represent the main objectives of the present work.

Following this introductory section, the rest of this paper is organized as follows. The next section presents a survey of the compressive strength-elastic modulus relationships proposed in the literature, and of possible size effects on the elastic modulus. Section 3 describes the details of experimental work performed in this study. Then, the size effects on elastic properties including static and dynamic moduli as well as the correlation between them are discussed. Section 5 deals with the relationship between compressive strength and Young's elastic modulus. Finally, some main conclusions of this study are presented in section 6 .

\section{Background}

To express the modulus of elasticity in terms of the compressive strength of concrete, numerous empirical formulas have been proposed by many researchers and/or are provided in the current concrete building design codes. Most of them 
focus on a possible correlation between the compressive strength with the static elastic Youngs's modulus $\left(Y_{S}\right)$, which are measured from uniaxial compression tests. For instance, the ACI committee recommends different empirical formulas relating the elastic modulus to the compressive strength and the density of concrete. The standard ACI 318-05 [3] gives the following expression for the Young's modulus of normal-weight concrete:

$$
Y_{s}=0.043 \cdot \rho^{1.5} \cdot \sqrt{f_{c}^{\prime}}
$$

where $Y_{S}$ is the static modulus of elasticity in MPa, $\rho$ is the density in $\mathrm{kg} / \mathrm{m}^{3}$ (for $1440 \leq \rho \leq 2560 \mathrm{~kg} / \mathrm{m}^{3}$ ) and $f_{c}^{\prime}$ is the specified compressive strength of cylindrical concrete samples in MPa. Equation (1) is valid for $f_{c}^{\prime}$ up to $41 \mathrm{MPa}[3$, 7]. Moreover, the ACI 363 committee [27] provides a different empirical equation to relate $Y_{s}$ and $f_{c}^{\prime}$ for both normal and high strength concrete with a range of $f_{c}^{\prime}$ between $21 \mathrm{MPa}$ and $83 \mathrm{MPa}$ :

$$
Y_{s}=\left(\frac{\rho}{2300}\right)^{1.5} \cdot\left(3320 \sqrt{f_{c}^{\prime}}+6900\right)
$$

According to EN 1992 [2], the relationship between the static modulus $\left(Y_{s}\right)$ and the compressive strength $\left(f_{c m}\right)$ of normal-weight concrete is described by the following equation:

$$
Y_{s}=22 \cdot\left(\frac{f_{c m}}{10}\right)^{0.3}
$$

where $Y_{s}$ is measured in GPa and $f_{c m}$ is in MPa. Equation (3) is suggested to be applicable up to concrete characteristic strengths of $90 \mathrm{MPa}[2,5]$. Both the ACI standards and EN 1992 express the static modulus of elasticity in terms of the secant modulus $\left(Y_{S}\right)$, but they differ in their definitions. The expression of the ACI standards (e.g. ACI 318-05 (Eq. (1)) and ACI 363-11 (Eq. (2))) are based on the specified compressive strength $\left(f_{c}^{\prime}\right)$, while EN 1992 (Eq. (3)) is based on the mean compressive strength $\left(f_{c m}\right)$ which is generally higher than the specified strength $[5$, $7,28]$. Moreover, the secant modulus $\left(Y_{S}\right)$ is defined as the slope of a line drawn from a zero stress to a compressive stress equal to $0.45 f_{c}^{\prime}$ in ACI 318-05 [3], and $0.4 f_{c m}$ in EN 1992 [2]. As for the ACI building codes, the Architectural Institute of Japan (AIJ) propose the following equation to estimate the static elastic modulus $\left(Y_{s}\right)$ for normal strength concrete with the specified design strength $\left(f_{c}^{\prime}\right)$ up to 36 $\operatorname{MPa}[6,29]$ : 


$$
Y_{S}=21000 \cdot\left(\frac{\rho}{2300}\right)^{1.5}\left(\frac{f_{c}^{\prime}}{200}\right)^{0.5}
$$

In Eq. (4), $Y_{s}$ and $f_{c}^{\prime}$ are expressed in $\mathrm{MPa}$ and $\rho$ is in $\mathrm{kg} / \mathrm{m}^{3}$. Unlike the ACI codes, Eurocode 2 and AIJ codes where the compressive strength is obtained from concrete cylinders with a height-to-diameter ratio $(h / \phi=2)$, the British standard BS 8110-2 [10] uses the characteristic strength of concrete cubes at 28 days $\left(f_{c u, 28}\right)$ to estimate the static modulus of elasticity at 28 days as follows:

$$
Y_{s, 28}=K_{0}+0.2 f_{c u, 28}
$$

Here $Y_{s, 28}$ is in GPa and $f_{c u, 28}$ is in $\mathrm{MPa}, K_{0}$ is an empirical constant related to the elastic modulus of the aggregate and to its volume fraction [10], usually taken as $20 \mathrm{GPa}$ for normal-weight concrete. In fact, the experimental value of $K_{0}$ varying from 16 to $26 \mathrm{GPa}$ was observed for normal-weight concretes fabricated from different aggregate types (see reviews in [30]). This wide variation of $K_{0}$ value implies that (i) different aggregates will cause different characteristic stiffness of concrete (i.e. the elastic modulus $Y_{s, 28}$ in Eq. (5)); and (ii) concretes with the same target compressive strength (i.e. strength grade) may have different elastic moduli. Other empirical formulas relating the compressive strength to the elastic modulus can be found in other current building codes (see further details in [5, 6, 8, 26, 31]) and from other studies, such as those presented in Table 1. Even though these empirical formulas could provide good agreements for specific kinds of concrete mixes, they do not always give the same results and cannot cover the whole data [6, 26]. The major reason for this is that the mechanical properties (i.e. compressive strength and elastic modulus) of concrete are highly dependent on the qualities, specified properties and proportions of all concrete components [5, 6, 8, 26]. Although there is no agreement on the precise form of the relationship between the compressive strength and the static modulus of elasticity of concrete, all these previous studies agree that the static Young's modulus and the compressive strength are always positively correlated $[5,7,32]$. A similar trend is also reported in [22, 25, 33-36] for the dynamic Young's modulus $\left(Y_{d}\right)$ which is determined by means of Non-Destructive Testing (NDT) methods (e.g. Ultrasonic pulse velocity (UPV) test [37], Resonant frequency test [38], and other wave propagation tests [5, 3941]). A few formulas have also been proposed in the literature to describe the relationship between $Y_{d}$ and the compressive strength of concrete, as listed in Table 
2. These empirical equations were found by converting the dependency of the static modulus on the dynamic modulus into the relationship between the static modulus and the compressive strength [24, 25, 42]. However, both the value of the dynamic elastic modulus and its relation with the compressive strength vary with the NDT methods [5, 43], the mix proportion [39], the volume content and the size of aggregates [24, 25], the type of cement and aggregate [24], the water-to-cement ratio [25, 35, 44], the age of concrete and curing condition [25, 35, 36, 39]. Consequently, the empirical expressions of the correlation between the compressive strength and the dynamic elastic modulus are generally specific to concrete mixes and/or distinct NDT methods used for investigating the $Y_{d}$-value $[5,22,39]$.

As mentioned above, to evaluate the correlation between the compressive strength of concrete and the elastic properties determined from the NDT methods (i.e. dynamic modulus of elasticity), the relationship between the compressive strength and the static elastic modulus as well as the relationship between the static and dynamic elastic moduli are required [24]. Consequently, a considerable number of studies has been performed to analyze the correlation between $Y_{S}$ and $Y_{d}[5,39]$. All these investigations highlighted that the static modulus of elasticity $\left(Y_{s}\right)$ is significantly smaller than the dynamic elastic modulus $\left(Y_{d}\right)[5,22,34]$. To account for the relationship between $Y_{s}$ and $Y_{d}$, several empirical formulas have been proposed in building codes. A linear correlation is generally proposed, while few studies suggest a non-linear expression (e.g. Lambert function [35]) (see Table 3). Several influence factors on the $Y_{S}-Y_{d}$ relation have been observed such as the loading rate in the static test [45], the NDT methodology [22], the aggregate volume content and maximum size of coarse aggregate [25]. On the other hand, the cement type and concrete age do not seem to have a significant influence [35].

Expressions (1) to (5) above represent various versions of a direct dependence of the Young's modulus on the compressive strength of concrete. Following these expressions, size effects on the compressive strength would necessarily imply a size-dependence of the elastic modulus of concrete. This is in contradiction with the general assumption that the modulus of elasticity, a linear property of a material, is actually sample size-independent. However, this assumption has not yet been clearly examined and/or confirmed, and there are contradictions between reported data in the literature. For instance, by analyzing 214 pairs of static Young's modulus values for two sizes of normal-weight concrete specimens (100x200 and 150x300 
mm cylinders) collected from the existing literature, Rashid et al. [31] observed that the $Y_{S}$ values obtained from the smaller-size samples are in general larger than those obtained from larger-size samples. An opposite result was however observed for high-performance concrete in [46]. In [22, 42], also comparing the $Y_{s}$ values of these two sizes of cylinders, Lee and co-workers did not find any clear sample size effect on both the static and dynamic elastic moduli of normal weight concrete. It is worth noting, however, that a precise assessment of size effects from only two different sample sizes is difficult. Performing uniaxial compression tests on concrete cylindrical specimens of five different diameters ranging from 63.5 to $300 \mathrm{~mm}$ but with a fixed heigh-to-diameter ratio $(h / \phi=2)$, Darlington et al. [21] observed that there is no evidence for a strong size effect on the static Young's modulus. Despite a larger range of system sizes, the restricted number of concrete samples $(<10$ samples for each size) tested in this study, combined with a large variability of $Y_{S}$ values for a given size, limits the statistical significance of the conclusion. This calls for more extensive data and further research on these possible size effects on the elastic modulus of concrete. The limited number of tests generally performed comes from the fact that this kind of experimental program is time- (e.g. due to the installation of the equipment to measure the sample deformation) and costconsuming.

From this survey of the literature several important questions arise:

(a) Does the elastic modulus of concrete depend on sample size?

(b) Is there any influence of sample size on the relationship between the static and dynamic elastic moduli of concrete?

(c) Considering well-established size effects on compressive strength [14, 15, 19] in one hand, and the proposed empirical relationships between compressive strength and elastic modulus (equations (1) to (5)), what could be the implications in terms of the estimation of elastic properties of concrete from strength data? And consequently in terms of design of concrete structural elements?

Motivated by those questions, we carried out an extensive experimental program on 527 cylindrical concrete specimens of three different concrete mixes and four different sample sizes. The details of the experimental research are described in the next section.

\section{Experimental work}


To address the main questions of the present research, a testing plan was designed to explore the size effects on the compressive strength and on the elastic modulus of concrete, as shown in the flowchart of Fig. 1. According to the recommendations in $[11,14,47,48]$, concrete specimens of the same composition and of at least three different sizes with a minimum size range of 1:4 should be used to investigate the size effects on mechanical strength. In the present work, concrete cylinders with a constant height-to-diameter ratio $(h / \phi=2)$ and four different sizes $(\phi=40,70,110,160 \mathrm{~mm})$ were fabricated from three different concrete mixtures based on three different aggregate sizes. The experimental study included both non-destructive and destructive tests. The aim of the non-destructive tests was to determine the dynamic modulus of elasticity. For this purpose, $36 \mathrm{P}$-wave velocity measurements (section 3.3) were conducted on intact concrete specimens. In addition, a series of 527 uniaxial compression tests (section 3.4), including the 36 samples previously used for P-wave velocity tests, were performed on all these concrete specimens. These destructive tests allowed to collect the values of both compressive failure strength and static modulus of elasticity for the different concrete samples. While the static modulus of elasticity is shown here for the first time, the compressive strength data have been used in [19] to analyze the size effects on compressive strength. In the present paper, all these data are used to examine: (i) the size effects on both static and dynamic elastic moduli of concrete; (ii) the correlation between these two estimations of the Young's modulus; and (iii) their relationships with the compressive strength.

\subsection{Materials and concrete mixtures}

In this work, a CEM I 52.5N type Portland cement satisfying the standard NF EN 197-1 [49] was used for preparing all concrete mixtures. Natural sand and gravel were used as the fine and coarse aggregates, respectively. All the aggregates used for concrete casting were clean and dry, and their specific properties complied with the requirements in NF EN 12620 [50] and NF EN 1097-5 [51] standards. The size distribution of aggregates (shown in Fig. 2a) was investigated from a sieving analysis following NF EN 933-1 [52]. Normal tap water was used for mixing and curing of concrete samples in this study. Applying the weight method described in the regulation NF-EN 206-1 [53], we prepared three different concrete mixtures based on three different aggregate sizes (Fine (F; i.e. only sand), Medium (M), 
Coarse $(\mathrm{C})$ ). The maximum aggregate size, $d_{g}$, for the F-, M-, and C-concrete mixtures were correspondingly $3.15 \mathrm{~mm}, 16 \mathrm{~mm}$ and $25 \mathrm{~mm}$ (see Fig. 2b). The water-to-cement $(W / C)$ ratio was kept unchanged for all specimens in each individual concrete mixture. The details of the mix proportions for the three concrete mixtures are given in Table 4.

\subsection{Concrete samples}

In this study, four different sizes of concrete cylinders $(\phi \times h=40 \times$ $80 \mathrm{~mm} ; 70 \times 140 \mathrm{~mm} ; 110 \times 220 \mathrm{~mm}$ and $160 \times 320 \mathrm{~mm}$ ) were considered. For a given concrete mixture, about 44 samples of each sample diameter $(\phi)$, were produced and used for uniaxial compression tests (section 3.4). The concrete mixing, casting and curing conformed to the procedure described in the standard NF EN 206-1 [53]. After weighting all raw composition materials, cement and aggregates are firstly blended for dry mix. After that, a small quantity of water is added and mixed for a while. Finally, remaining water is added and continuously mixed before pouring into the concrete molds. All the concrete samples were cast in cylindrical cardboard molds (see Fig. 3a), and then compacted on an external vibrating table combined with an internal vibrator for improving the consolidation of the samples. After compaction, the tops of the samples were smoothly finished by using a trowel and then covered by polyethylene sheets.

All concrete specimens were kept in their molds for 48 hours after casting in a moisture room in accordance with the recommendation of the regulation NF EN 12390-2 [54]. After this period, the concrete cylinders were taken out of their molds and continuously cured by immersing them in a water basin at a temperature of approximately $20^{\circ} \mathrm{C}$ for 2 months. At the age of 56 days, all the specimens were cut by diamond grinding discs to ensure both the ends to be perpendicular to the sides of the sample and avoid flexural stresses upon loading. After sawing, the concrete specimens were kept again in the water basin for an additional month and left exposed to atmosphere in the laboratory until the testing day (see Fig. 3b). In accordance with the recommendation of the regulation NF EN 12390-3 [55], compression tests should be carried out after a minimum age of 28 days. In this research, all the compression tests were performed five months after concrete casting. 


\subsection{P-wave velocity measurements}

According to ASTM C597-02 [37], the dynamic Young's modulus of concrete can be estimated from the P-wave velocity, $V_{p}$, of a compression wave travelling through an elastic concrete body, the Poisson's ratio, $v$, and the density of the concrete sample, $\rho$, as follows:

$$
Y_{d}=V_{p}^{2}\left[\frac{\rho(1+v)(1-2 v)}{1-v}\right]
$$

In this study, based on the principles of ultrasonic testing described in ASTM C597-02 [37], the transit time, $\Delta_{t}$, of P-waves through the concrete sample was measured by using an Acoustic Emission (AE) equipment (see Fig. 4c and Fig. 5a). The velocity, $V_{p}$, was then calculated by dividing the wave path, $h$, (the height of concrete sample) over the transit time, $\Delta t$, as $V_{p}=h / \Delta t$. These P-wave velocity measurements were non-destructive tests and carried out on intact concrete specimens prior to uniaxial compression tests (section 3.4). For this work, a total of 36 specimens (three specimens for a given size and type of concrete) were tested.

In order to detect the arrival time of $\mathrm{P}$-wave of concrete, a pair of piezoelectric transducers (AE sensors) with frequency bandwidth of $20-1200 \mathrm{kHz}$ was used. These two transducers were fixed to the ends of concrete cylinder by applying a coupling silicon paste (see Fig. 4c). In this study, Pencil-lead break (PLB) (HsuNielsen source [56]) was used as an artificial method of generating acoustic emission (AE) signals. The PLBs occurring very close to one of the two transducers, caused stress waves that propagated through the concrete sample and then recorded by the remaining transducer (see Fig. 4c and Fig. 5a). Five different PLB tests were conducted around each $\mathrm{AE}$ sensor, for a total of 10 values of $\mathrm{P}$-wave velocity collected for each concrete sample. The transit time, $\Delta t$, in each PLB test was computed as the difference of arrival time of the P-wave between the two AE sensors. The details of these AE measurements have been presented elsewhere [19].

It is noteworthy that the $\mathrm{S}$-waves were hardly distinguishable from the $\mathrm{P}$-waves on the waveforms recorded by the $\mathrm{AE}$ system [57, 58]. Consequently, the measurement of the shear modulus, and so of the Poisson's ratio $(v)$, was not possible from the AE measurements carried out in this study. As reported in $[5,39$, 59-61], the value of Poisson's ratio for normal-weight concrete is generally in a range 0.20 to 0.25 . Moreover, available data do not show any significant impact of 
various factors (e.g. $W / C$ ratio, curing condition, aggregate gradation) on Poisson's ratio $[5,7]$. Similarly, published data show no evidence of shape or size effects on Poisson's ratio [21, 39, 59]. In this study, an averaged value of $v=0.22$ was assumed as the value of Poisson's ratio for all our concretes to estimate the dynamic modulus of elasticity $\left(Y_{d}\right)$ from Eq. (6).

\subsection{Uniaxial compression test}

After completing the nondestructive tests (section 3.3), static mechanical properties including the compressive strength and the static modulus of elasticity of concrete specimens were determined from a series of uniaxial compression tests. These loading tests were carried out following the procedure described in the regulations NF EN 12390-3 [55]. In this work, two load-controlled compression machines (of different stiffness and loading capacity) were used because the concrete samples were of different sizes. These two machines were calibrated and certified by the French Accreditation Committee (COFRAC) [62] and their specific properties conformed to the requirements in the regulation NF EN 12390-4 [63]. For the three large sample sizes (cylinders of $70 \mathrm{~mm}, 110 \mathrm{~mm}$, and $160 \mathrm{~mm}$ in diameter), a compression machine (Machine A, Fig. 4a) with a loading capacity of $3000 \mathrm{kN}$ was used. This machine is 2.9 stiffer than the largest specimens. The other compression machine (Machine B, Fig. 4b) with a loading capacity of $300 \mathrm{kN}$ was used for the smallest samples (cylinders of $40 \mathrm{~mm}$ in diameter). The stiffness of this machine is 3.5 times that of the $40 \times 80-\mathrm{mm}$ specimens. The loading rate applied for all compression tests was $0.5 \mathrm{MPa}$ per second and kept unchanged from the beginning of loading until the sample was broken down. When the load fell below $50 \%$ of the peak load, loading and data recording were automatically stopped. During the test, the load $(F)$, the stress $\left(\sigma=4 F / \pi \phi^{2}\right)$ and the axial displacement $(\delta)$ were continuously recorded every 0.2 seconds. The displacement $(\delta)$ was the axial displacement of the bottom steel platen of the compression machine and measured by one Linear Variable Differential Transducer (LVDT) attached on the frame of the machine. It is noteworthy that both the sample and the compression machine are deforming upon loading. Consequently, the axial displacement $(\delta)$ measured directly from the test, comprises not only the true axial displacement of the specimen $\left(\Delta_{s p}\right)$, but also the elastic deformation of the loading frame $\left(\Delta_{f r}\right)$. For this reason, to obtain the value of $\Delta_{s p}$, the elastic deformation $\left(\Delta_{f r}\right)$ must be 
eliminated from the measured displacement $(\delta)$. In the present work, we performed a calibration test on an Aluminum sample of known elastic modulus to determine the relationship between the loading deformation $\left(\Delta_{f r}\right)$ and the applied load $(F)$. In other words, from this calibration test, the elastic deformation of the compression machine $\left(\Delta_{f r}\right)$ was calculated at any applied load and then used to correct the true displacement corresponding to the deformation of the concrete sample $\left(\Delta_{s p}\right)$. The details of these calibration tests have been presented elsewhere [62].

\subsection{Determination of static elastic modulus}

The static Young's modulus is generally defined as the elastic stiffness that relates to the ratio of axial stress to axial strain for a material subjected to uniaxial loading [5]. Various estimations of this static modulus from the slope of the stressstrain curve in the elastic deformation regime have been proposed, such as the tangent modulus [7, 64], the secant modulus $[2,3,65]$ or the chord modulus [66]. In this study, both the secant and tangent elastic moduli for all concrete specimens were examined. The deformation of a concrete specimen is calculated by dividing the displacement, $\Delta_{s p}$, (see section 3.4) by the height of specimen $\left(\varepsilon=\Delta_{s p} / h\right)$. Fig. 5b shows an example curve of the stress-strain relation for our concrete samples in a compression test.

In order to estimate the tangent elastic modulus of concrete, we defined the tangent modulus, $\left(Y_{t}\right)_{i}$ at a data point $i$ from a differentiation of the stress-strain curve:

$$
\left(Y_{t}\right)_{i}=\frac{\sigma_{i+1}-\sigma_{i}}{\varepsilon_{i+1}-\varepsilon_{i}}
$$

A 40 data points moving average of this $\left(Y_{t}\right)_{i}$ curve was then performed, and the maximum value of this moving average is taken as the tangent modulus, $Y_{t}$, of the concrete sample examined (see Fig. 5b). In the present work, the secant elastic modulus, $Y_{S}$ was computed by the slope of a line drawn from the origin to $40 \%$ of the peak stress in accordance with the recommendation described in the standard EN 1992 [2]. 


\section{Size effect on elastic moduli}

Concrete, a typical heterogeneous material, exhibits a size-dependent behavior on the nominal compressive strength [11]. Precisely, the compressive strength decreases, in average, with increasing sample size. For the concretes used in this study, the size effect on compressive strength has also been confirmed and thoroughly analyzed elsewhere [19]. In this paper, we focus on the effect of size on the Young's modulus of concrete. This work considers both static and dynamic estimations of elastic (Young's) moduli as well as the relationship between them.

The variations of static elastic moduli $Y_{t}$ and $Y_{s}$ with the sample diameter for the three concrete groups are respectively presented in Fig. 6a and Fig. 6b. As displayed in Fig. 6c, the tangent modulus, $Y_{t}$, is observed to be approximately equal to the secant modulus, $Y_{S}$, regardless of sample size and concrete mixture, meaning that below $40 \%$ of the peak load, all our concretes remain essentially in the elastic domain. The mean values and the corresponding standard deviation (SD) of static elastic moduli $Y_{t}$ and $Y_{s}$ for different sample sizes of our three concrete mixtures are summarized in Table 5. As expected, the coarser materials (M- and C-concretes) show the higher values of both the mean and the associated variability of tangent and secant moduli compared to the finer ones (F-concrete). For a given concrete mixture, the static elastic properties, including tangent and secant moduli and their standard deviations, do not exhibit any significant sample size effect.

As already presented in [19], from the non-destructive measurements (section 2.3), we observed no significant dependence of both P-wave velocities, $V_{p}$, and dynamic elastic moduli, $Y_{d}$, as well as their associated variabilities, on sample size (see Fig. 11 in [19]). The absence of sample size effect on the elastic properties including the P-wave velocity, static (section 3.1), and dynamic elastic moduli means that all the concrete samples tested, including the smallest ones (40x80mmsamples), are large enough in terms of microstructural characteristics to be statistically representative of the linear (e.g. elastic) mechanical properties of the materials [20]. The mean values of $\mathrm{P}$-wave velocity $\left(V_{p}\right)$ and dynamic elastic modulus $\left(Y_{d}\right)$ for different sample sizes of the three concrete groups are reported in Table 5 .

As shown on Fig. 7, the static elastic moduli $Y_{t}$ and $Y_{s}$ are observed to be systematically smaller than the dynamic elastic modulus, $Y_{d}$, regardless of concrete 
mixture and sample size, with a proportionality coefficient of $0.6\left(Y_{t, s} \sim 0.6 Y_{d}\right)$. Nevertheless, it is noteworthy that the values of $Y_{t}$ and $Y_{s}$ in this study were derived from the deformation of the whole height of the concrete specimen (see section 2.4). As recommended in [67], in order to determine a proper value of the static elastic moduli $Y_{t, s}$, the deformation should be measured over the central third of the specimen height. According to Mansur et al. [68], the static modulus of elasticity estimated by the deformation measured from the central region of the concrete specimen is approximately 1.35 times higher than the deformation measured between the loading platens (similar to our case). Therefore, if we use the correction coefficient of 1.35 for the all values of $Y_{t, s}$, the linear relation in Fig. 7 becomes $Y_{t, s} \sim 0.8 Y_{d}$. This is consistent with empirical relationships between static and dynamic moduli presented in $[5,69]$.

The difference between static and dynamic moduli might be related to the fact that the heterogeneous characteristics of concrete influence these two moduli in different manners [70]. Indeed, by means of a nondestructive technique (section 2.3), the dynamic modulus of elasticity is determined prior to loading and so without microcracking induced in the concrete specimen during the test. Consequently, the dynamic modulus refers to the genuine elastic properties of the material, while the static modulus can be affected by permanent non-linear deformations resulting from damage and microcracking $[5,71]$. For this reason, the dynamic modulus is considered to be approximately equal to the initial tangent modulus determined in the static test $[5,7]$. This explains why the elastic static modulus, $Y_{t}$ and/or $Y_{s}$, is generally smaller than the elastic dynamic modulus, $Y_{d}$, (or initial tangent modulus).

It should be noted that the value of Young's modulus of concrete, obtained from both static and dynamic measurements, could be affected by many other factors such as moisture content and density [5, 7]. For our concretes, the procedure to determine the moisture content and density has been presented in details elsewhere [28]. However, for a given concrete group, we did not observe any significant sample size effects on both density and moisture content (see their values in Table 5). This means that both the moisture content and density neither have a significant influence on the size-dependency of the elastic modulus of concrete, nor on the correlation between the static and dynamic elastic moduli. 


\section{Relationship between compressive strength and elastic (Young's) modulus}

As mentioned in section 1, there are numerous empirical expressions given in the current building codes and/or proposed in the literature to estimate the elastic modulus based on the compressive strength of concrete. In this study, only the expressions proposed in the most popular building codes (i.e. the standards EN 1992 [2] and ACI 318-05 [3]) are used in order to compare with our results.

As displayed in Eqs. (1) and (3) as well as for other equations summarized in Table 1 , it is clear that these empirical formulas are dimensionally conflicting (e.g. Pa vs. $\mathrm{Pa}^{0.5}$ in Eq. (1) and $\mathrm{Pa} v s . \mathrm{Pa}^{0.3}$ in Eq. (3)). Besides this, Fig. 8, which shows the correlations between the compressive strength, $\sigma_{f}$, and the static $\left(Y_{t}\right.$ and $\left.Y_{s}\right)$ and dynamic $\left(Y_{d}\right)$ elastic moduli for all of our concrete samples, epitomizes several problems while using such empirical relations. In this figure, we show the modulus of elasticity (static and dynamic)-compressive strength relationships for all our concrete samples. The relationships obtained using the expressions (Eqs. (1) and (3)) given in the codes mentioned above are also plotted in Fig. 8 by taking $\left(f_{c}^{\prime}=\sigma_{f}\right)$ and $\left(f_{c m}=\sigma_{f}\right)$. From this, we observed that:

(i) for the static modulus of elasticity, the empirical expressions are systematically much larger than our values of both $Y_{t}$ and $Y_{s}$, regardless of concrete mixture and sample size.

(ii) for the dynamic modulus of elasticity, $Y_{d}$, experimental data are below the empirical predictions for F-concrete, but above the predictions for $\mathrm{M}$ - and $\mathrm{C}$ concretes. In other words, for M- and C-concretes, both EN 1992 and ACI 318-05 underestimate the value of $Y_{d}$ while these empirical predictions overestimate it for F-concrete.

(iii) the mean value of the dynamic modulus of elasticity, $Y_{d}$, seems to slightly increase with increasing compressive strength, $\sigma_{f}$, for F- and M-concretes (see Fig. $8 \mathrm{a}$ and $\mathrm{b}$ ). This is not the case for C-concrete (Fig. 8c) and, gathering the data obtained for all sample sizes for a specified concrete mixture in Fig. 8d, an opposite trend is actually observed. This means that, due to size effects on compressive strength, there is no correlation between the dynamic modulus of elasticity and the compressive strength, in contrast with the empirical expressions summarized in Table 2. 
(iv) for an individual dataset (fixed concrete mixture and sample size), the correlations of compressive strength $\sigma_{f}$ with both static moduli $Y_{t}$ and $Y_{s}$ are either very weak or unsignificant (see Table 6). Merging strength data for all sample sizes of a given concrete group, the absence of correlation is clear as well (see Fig. 8a, b and c). This is expected, as we observed a size effect on strength (see in more details in [19]) but not on the elastic modulus (Fig. 8).

(v) considering now all concrete samples (all sizes, all materials), the disagreement with the empirical formulas (1) and (3) is even more striking (Fig. 8d). Indeed, increasing the aggregate size implies an increase of the elastic modulus, as expected, while F-concrete showed, in average, larger strengths than $\mathrm{M}$ - and Cconcrete. As explained in more details in [19], this last point is a consequence of the size effects on compressive strength, in relation with the pore structure of our hardened concrete samples.

This demonstrates the absence of significant and meaningful link between elastic modulus (either static or dynamic) and compressive strength. This, we argue, is not surprising, given that the modulus of elasticity is directly related to elastic (linear) deformation, while the compressive strength is affected by the non-linear behavior due to the progressive development of damage and microcracking $[5,7]$. For a perfect crystalline material without defects, the ultimate (tensile) strength, resulting from pure brittle failure, would be proportional to the elastic modulus [72]. For a disordered material like concrete under compression, such scenario is unrealistic.

Nevertheless, it is noteworthy that the empirical expressions (e.g. Equations (1) and (3) or those summarized in Table 1) have been proposed from experimental datasets of only one standardized size of concrete sample (e.g. cylinder of 150x300 $\mathrm{mm}$ in US [73]; cylinder of 160x320 mm or cube of 150x150x150 mm in many European nations $[53,74]$; either cubes of $100 \times 100 \times 100 \mathrm{~mm}$ or $150 \times 150 \times 150 \mathrm{~mm}$ in other countries) with different concrete mixtures (i.e. different strength grades) $[5-7,26]$. These empirical expressions may thus actually express the influence of some factors such as aggregate type, density, or mix proportion on both the elastic properties and the compressive strength. They might therefore provide a relatively good estimation of the Young's modulus from the compressive strength in case of normal-weight concretes, as long as the concrete sample size used to measure the strength is in conformity with these standardized sizes [6]. In the present study, we 
examined the influence of sample size on the relationship between the modulus of elasticity and the compressive strength, while, by definition, the strength grade (i.e. the characteristic compressive strength) of a given concrete mixture is independent of sample size. From these observations, it can be concluded that, in order to estimate the Young's modulus from the compressive strength of concrete, in many cases (e.g. F-concrete samples in this study), due to the sample size effect on the compressive strength, the use of empirical expressions such as Eq. (1) or Eq. (3) may lead to an overestimation (an unsafe result). Owing to the limited number of different concrete mixtures considered in the present work and the similarity of their characteristic compressive strength (see [28] for more details), we cannot conclude that these empirical formulas could not be acceptable for other concrete mixtures (e.g. other type of concrete, other strength grade mixture). However, more generally, to measure the elastic modulus from a static load test, rather than from such empirical relations, is highly recommended and considered as being much safer for concrete structural design.

\section{Conclusion}

In this paper, from an extensive experimental study of the compressive behavior of different concrete mixtures and different sample sizes: we (i) explored a potential effect of sample size on the elastic properties (i.e. Young's modulus and P-wave velocity); and (ii) discussed the relationship between compressive strength and elastic modulus. The following main conclusions can be drawn:

(i) The coarser concrete shows a larger elastic modulus than the finer ones. This is consistent with the fact that the elastic modulus of concrete is affected by the elastic modulus of the aggregate and by the volumetric proportion of aggregate in the concrete.

(ii) The ratio of the static modulus of elasticity to the dynamic modulus for all specimens, regardless of sample size and concrete mixture, is always smaller than unity. Nevertheless, this ratio directly depends on the methodologies applied for measuring the deformation of specimens during the loading and for estimating the static elastic modulus. This means that there is no simple conversion between the dynamic modulus, which is known as the genuine elastic modulus of the material, and an estimate of the static modulus which is used in structural design. 
(iii) For a given concrete mixture, there is no sample size effect on the elastic properties of concrete, including the static and dynamic elastic moduli. This is in full contrast with the compressive strength, which exhibits significant size effects for all the concrete mixtures.

(iv) A consequence of point (iii) above is that there is no direct proportionality between elastic modulus (a size-independent property) and compressive strength (a size-dependent property) of concrete. This raises severe concerns about the use of empirical formulas proposed in building codes to estimate the Young's modulus from the compressive strength, and consequently on the design of structural concrete elements. Consequently, the authors recommend using non-destructive methods such P-wave velocity measurements or performing uniaxial compression tests on concrete specimens to directly determine the elastic modulus of concrete.

\section{Acknowledgements}

The authors gratefully acknowledge the support of the AGIR program from Grenoble Alpes University (UGA), France, for this research. We would also like to thank the technicians of UGA and USMB for their technical assistances.

\section{References}

1. Zhou FP, Lydon FD, Barr BIG (1995) Effect of coarse aggregate on elastic modulus and compressive strength of high performance concrete. Cem Concr Res 25:177-186. https://doi.org/10.1016/0008-8846(94)00125-I

2. EN 1992 (2004) Eurocode 2: Design of concrete structures - Part 1-1 : General rules and rules for buildings. European Committee for Standardization

3. ACI 318-05 (2005) Building Code Requirements for Structural Concrete and Commentary. American Concrete Institute

4. Parra C, Valcuende M, Gómez F (2011) Splitting tensile strength and modulus of elasticity of self-compacting concrete. Constr Build Mater 25:201-207. https://doi.org/10.1016/j.conbuildmat.2010.06.037

5. Neville AM, Brooks JJ (2010) Properties of concrete, 4th ed. Pearson Education Limited

6. Noguchi T, Tomosawa F, Nemati KM, et al (2009) A practical equation for elastic modulus of concrete. ACI Struct J 106:690-696. https://doi.org/10.14359/51663109

7. Mehta PK, Monteiro PJM (2006) Concrete: microstructure, properties, and materials, Third. McGraw-Hill

8. Nematzadeh M, Naghipour M (2012) Compressive strength and modulus of elasticity of freshly compressed concrete. Constr Build Mater 34:476-485. https://doi.org/10.1016/j.conbuildmat.2012.02.055

9. Béton CE-I du (1993) CEB-FIP Model Code 1990

10. (1985) BS 8110-2: 1985 Structural use of concrete - Part 2: Code of practice for special circumstances. 3

11. Bazant ZP, Planas J (1998) Fracture and size effect in concrete and other quasibrittle materials. CRC Press, Boca Raton, Florida, USA

12. Burtscher SL, Kollegger J (2003) Size-effect experiments on concrete in compression. Struct Concr 4:163-174 
13. Ozbolt J, Eligehausen R (1995) Size effect in concrete and reinforced concrete structures. Fract Mech Concr Struct 665-674

14. Bazant ZP (1999) Size Effect on Structural Strength: A Review. Arch Appl Mech 69:703725. https://doi.org/10.1007/s004190050252

15. Bazant ZP (1998) Size effect in tensile and compression fracture of concrete structures: Computational modeling and design. Fract Mech Concr Struct Proceeding: 1905-1922

16. Muciaccia G, Rosati G, Luzio G Di (2017) Compressive failure and size effect in plain concrete cylindrical specimens. Constr Build Mater 137:185-194. https://doi.org/10.1016/j.conbuildmat.2017.01.057

17. del Viso JR, Carmona JR, Ruiz G (2008) Shape and size effects on the compressive strength of high-strength concrete. Cem Concr Res 38:386-395. https://doi.org/10.1016/j.cemconres.2007.09.020

18. Weiss J, Girard L, Gimbert F, et al (2014) (Finite) statistical size effects on compressive strength. Proc Natl Acad Sci U S A 111:6231-6236. https://doi.org/10.1073/pnas.1403500111

19. Vu CC, Weiss J, Plé O, et al (2018) Revisiting statistical size effects on compressive failure of heterogeneous materials, with a special focus on concrete. J Mech Phys Solids 121:47-70. https://doi.org/10.1016/j.jmps.2018.07.022

20. Kanit T, Forest S, Galliet I, et al (2003) Determination of the size of the representative volume element for random composites : statistical and numerical approach. Int J Solids Struct 40:3647-3679. https://doi.org/10.1016/S0020-7683(03)00143-4

21. Darlington WJ, Ranjith PG, Choi SK (2011) The effect of specimen size on strength and other properties in laboratory testing of rock and rock-like cementitious brittle materials. Rock Mech Rock Eng 44:513-529. https://doi.org/10.1007/s00603-011-0161-6

22. Lee BJ, Kee SH, Oh T, Kim YY (2015) Effect of Cylinder Size on the Modulus of Elasticity and Compressive Strength of Concrete from Static and Dynamic Tests. Adv Mater Sci Eng 2015:. https://doi.org/10.1155/2015/580638

23. Vu C, Amitrano D, Pl O (2019) Compressive Failure as a Critical Transition : Experimental Evidence and Mapping onto the Universality Class of Depinning. Phys Rev Lett 122:6. https://doi.org/10.1103/PhysRevLett.122.015502

24. Jurowski K, Grzeszczyk S (2018) Influence of selected factors on the relationship between the dynamic elastic modulus and compressive strength of concrete. Materials (Basel) 11:1-12. https://doi.org/10.3390/ma11040477

25. Zhou Y, Gao J, Sun Z, Qu W (2015) A fundamental study on compressive strength, static and dynamic elastic moduli of young concrete. Constr Build Mater 98:137-145. https://doi.org/10.1016/j.conbuildmat.2015.08.110

26. Park WJ, Noguchi T, Shin SH, Oh DY (2015) Modulus of elasticity of recycled aggregate concrete. Mag Concr Res 67:585-591. https://doi.org/10.1680/macr.14.00213

27. ACI Committee 363 (2011) ACI 363.2R-11: Guide to Quality Control and Assurance of High-Strength Concrete. Am Concr Inst 23

28. Vu CC, Plé O, Weiss J, Amitrano D (2020) Revisiting the concept of characteristic compressive strength of concrete. Constr Build Mater 263:120126. https://doi.org/10.1016/j.conbuildmat.2020.120126

29. Architectural Institute of Japan (2010) AIJ Standard for Structural Calculation of Reinforced Concrete Structures

30. Alexander MG (1991) An experimental critique of the BS 8110 method of estimating concrete elastic modulus. Mag Concr Res 43:291-304

31. Rashid MA, Mansur MA, Paramasivam P (2002) Correlations between mechanical properties of high-strength concrete. J Mater Civ Eng 14:230-238. https://doi.org/10.1061/(ASCE)0899-1561(2003)15:5(511)

32. Oluokun FA, Burdette EG, Deatherage JH (1991) Elastic Modulus, Poisson's Ratio, and Compressive Strength Relationships at Early Ages. ACI Mater J 88:. https://doi.org/10.14359/2303

33. Tsioulou O, Lampropoulos A, Paschalis S (2017) Combined Non-Destructive Testing (NDT) method for the evaluation of the mechanical characteristics of Ultra High Performance Fibre Reinforced Concrete (UHPFRC). Constr Build Mater 131:66-77. https://doi.org/10.1016/j.conbuildmat.2016.11.068

34. Bassim R, Issa M (2020) Dynamic- and Static-Elastic Moduli and Strength Properties of Early-Age Portland Cement Concrete Pavement Mixtures. J Mater Civ Eng 32:04020066. https://doi.org/10.1061/(asce)mt.1943-5533.0003089

35. Han SH, Kim JK (2004) Effect of temperature and age on the relationship between dynamic and static elastic modulus of concrete. Cem Concr Res 34:1219-1227. 
https://doi.org/10.1016/j.cemconres.2003.12.011

36. Lee K-M, Kim D-S, Kim J-S (1997) Determination of dynamic Young's modulus of concrete at early ages by impact resonance test. KSCE J Civ Eng 1:11-18. https://doi.org/10.1007/bf02830459

37. ASTM C597-02 (2002) Standard Test Method for Pulse Velocity Through Concrete. ASTM International, West Conhohocken, PA

38. ASTM C215-14 (2014) Standard Test Method for Fundamental Transverse, Longitudinal, and Torsional Resonant Frequencies of Concrete Specimens

39. Malhotra WM, Carino NJ (2004) Hanbook on Nondestructive testing of concrete, 2nd ed. CRC Press, West Conhohocken, PA

40. Krzemien K, Hager I (2015) Post-fire assessment of mechanical properties of concrete with the use of the impact-echo method. Constr Build Mater 96:155-163. https://doi.org/10.1016/j.conbuildmat.2015.08.007

41. (2013) ACI 228.2R-13: Report on Nondestructive Test Methods for Evaluation of Concrete in Structures. American Concrete Institute

42. Lee BJ, Kee SH, Oh T, Kim YY (2017) Evaluating the Dynamic Elastic Modulus of Concrete Using Shear-Wave Velocity Measurements. Adv Mater Sci Eng 2017:. https://doi.org/10.1155/2017/1651753

43. Kee SH, Kang JW, Choi BJ, et al (2019) Evaluation of static and dynamic residual mechanical properties of heat-damaged concrete for nuclear reactor auxiliary buildings in Korea using elasticwave velocity measurements. Materials (Basel) 12:. https://doi.org/10.3390/ma12172695

44. Kumar S, Rai B (2019) Pulse velocity-strength and elasticity relationship of high volume fly ash induced self-compacting concrete. J Struct Integr Maint 4:216-229. https://doi.org/10.1080/24705314.2019.1657615

45. Shkolnik IE (2005) Effect of nonlinear response of concrete on its elastic modulus and strength. Cem Concr Compos 27:747-757. https://doi.org/10.1016/j.cemconcomp.2004.12.006

46. Baalbaki W, Baalbaki M, Benmokrane B, Aitcin PC (1992) Influence of specimen size on compressive strength and elastic modulus of high-performance concrete. Cem Concr Aggregates 14:113-117

47. Shah SP (1990) Size-effect method for determining fracture energy and process zone size of concrete. Mater Struct 23:461-465. https://doi.org/10.1007/BF02472030

48. Carpinteri A, Ferro G, Monetto I (1999) Scale effects in uniaxially compressed concrete specimens. Mag Concr Res 51:217-225. https://doi.org/10.1680/macr.1999.51.3.217

49. NF EN 197-1 (2012) Ciment -Partie 1: Compostition, spécifications et critères de conformité des ciments courants. Association Française de Normalisation (AFNOR)

50. NF EN 12620 (2008) Granulats pour béton. Association Française de Normalisation (AFNOR)

51. NF EN 1097-5 (2008) Essais pour déterminer les caractéristiques mécaniques et physiques des granulats - Partie 5 : détermination de la teneur en eau par séchage en étuve ventilée. Association Française de Normalisation (AFNOR)

52. NF EN 933-1 (2012) Essais pour déterminer les caractéristiques géométriques des granulats - Partie 1 : détermination de la granularité - Analyse granulométrique par tamisage. Association Française de Normalisation (AFNOR)

53. NF EN 206-1 (2004) Béton - Partie 1 : Spécification, performances, production et conformité. Association Française de Normalisation (AFNOR)

54. NF EN 12390-2 (2012) Essais pour béton durci - Partie 2: Confection et conservation des éprouvettes pour essais de résistance. Association Française de Normalisation (AFNOR)

55. NF EN 12390-3 (2012) Essais pour béton durci - Partie 3 : Résistance à la compression des éprouvettes. Association Française de Normalisation (AFNOR)

56. ASTM E976-10 (2010) Standard Guide for Determining the Reproducibility of Acoustic Emission Sensor Response. ASTM Int West Conshohocken, PA

57. Mindess S (2004) Acoustic Emission Methods. In: Malhotra VM, Carino NJ (eds) Handbook on Nondestructive testing of concrete, 2nd ed. \&5\&_3UHVV_//\&_, Boca Raton, Florida, USA, pp 348-365

58. Ohtsu M (2015) Acoustic Emission (AE) and Related Non-destructive Evaluation Techniques in the Fracture Mechanics of Concrete: Fundamentals and Applications. Elsevier, Cambridge, CB22 3HJ, UK

59. Anson M, Newman K, Mayfield B (1966) The effect of mix proportions and method of testing on Poisson's ratio for mortars and concretes. Mag Concr Res 18:115-130. https://doi.org/10.1680/macr.1967.19.59.118 
60. Sideris KK, Manita P, Sideris K (2004) Estimation of ultimate modulus of elasticity and Poisson ratio of normal concrete. Cem Concr Compos 26:623-631. https://doi.org/10.1016/S0958-9465(03)00084-2

61. Petro JT, Kim J (2012) Detection of delamination in concrete using ultrasonic pulse velocity test. Constr Build Mater 26:574-582.

https://doi.org/10.1016/j.conbuildmat.2011.06.060

62. Vu CC, Weiss J, Plé O, Amitrano D (2020) Size effects on the mechanical behavior and the compressive failure strength of concrete: an extensive dataset. Data $\mathrm{Br} 33$ :. https://doi.org/10.1016/j.dib.2020.106477

63. NF EN 12390-4 (2000) Essais pour béton durci - Partie 4 : Résistance à la compression Caractéristiques des machines d'essai. Association Française de Normalisation (AFNOR)

64. Fib Mode Code (2013) fib Mode Code for Concrete Structures 2010. Wilhelm Ernst \& Sohn

65. NF EN 12390-13 (2014) Essais pour béton durci — Partie 13 : Détermination du module sécant d'élasticité en compression. Association Française de Normalisation (AFNOR)

66. ASTM C469/C469M-14 (2014) Standard Test Method for Static Modulus of Elasticity and Poisson's Ratio of Concrete in Compression. ASTM Int West Conshohocken, PA. https://doi.org/10.1520/C0469_C0469M

67. RILEM TC 148-SSC (2000) Strain softening of concrete: Test method for measurement of the strain-softening behaviour of concrete under uniaxial compression

68. Mansur MA, Wee TH, Chin MS (1995) Derivation of the complete stress - strain curves for concrete in compression. Mag Concr Res 47:285-290. https://doi.org/10.1680/macr.1995.47.173.285

69. Lydon FD, Balendran R V (1986) Some observations on elastic properties of plain concrete. Cem Concr Res 16:314-324

70. Philleo RE (1955) Comparison of results of three methods for determining Young's modulus of elasticity of concrete. ACI J Proc 51:. https://doi.org/10.14359/11690

71. Linger DA (1963) Effect of stress on the dynamic modulus of concrete. Highw Res Rec Prop Concr 62-73

72. Miannay DP (1998) Fracture Mechanics. Springer, Berlin, Germany

73. ASTM C39/C39M-14 (2014) Standard Test Method for Compressive Strength of Cylindrical Concrete Specimens. ASTM Int 1-7. https://doi.org/10.1520/C0039_C0039M14

74. NF EN 12390-1 (2012) Essais pour béton durci - Partie 1 : Forme, dimensions et autres exigences relatives. Association Française de Normalisation (AFNOR)

75. Ahmad SH, Shah SP (1985) Structural Properties of High Strength Concrete and Its Implications for Precast Prestressed Concrete. PCI J 30:92-119.

https://doi.org/10.15554/pcij.11011985.92.119

76. Kakizaki M, Edahiro H, Tochigi T, Niki T (1992) Effect of Mixing Method on Mechanical Properties and Pore Structure of Ultra High-Strength Concrete

77. Iravani S (1996) Mechanical properties of high-performance concrete. ACI Mater J 93:416-426

78. Malaikah AS (2005) A Proposed Relationship for the Modulus of Elasticity of High Strength Concrete Using Local Materials in Riyadh. J King Saud Univ Eng Sci 17:131141. https://doi.org/10.1016/S1018-3639(18)30804-3

79. Popovics S (1975) Verification of relationships between mechanical properties of concrete-like materials. Matériaux Constr 8:183-191. https://doi.org/10.1007/BF02475168

80. Pešić N, Živanović S, Dennis J, Hargreaves J (2015) Experimental and finite element dynamic analysis of incrementally loaded reinforced concrete structures. Eng Struct 103:15-27. https://doi.org/10.1016/j.engstruct.2015.07.037 


\section{Figures}
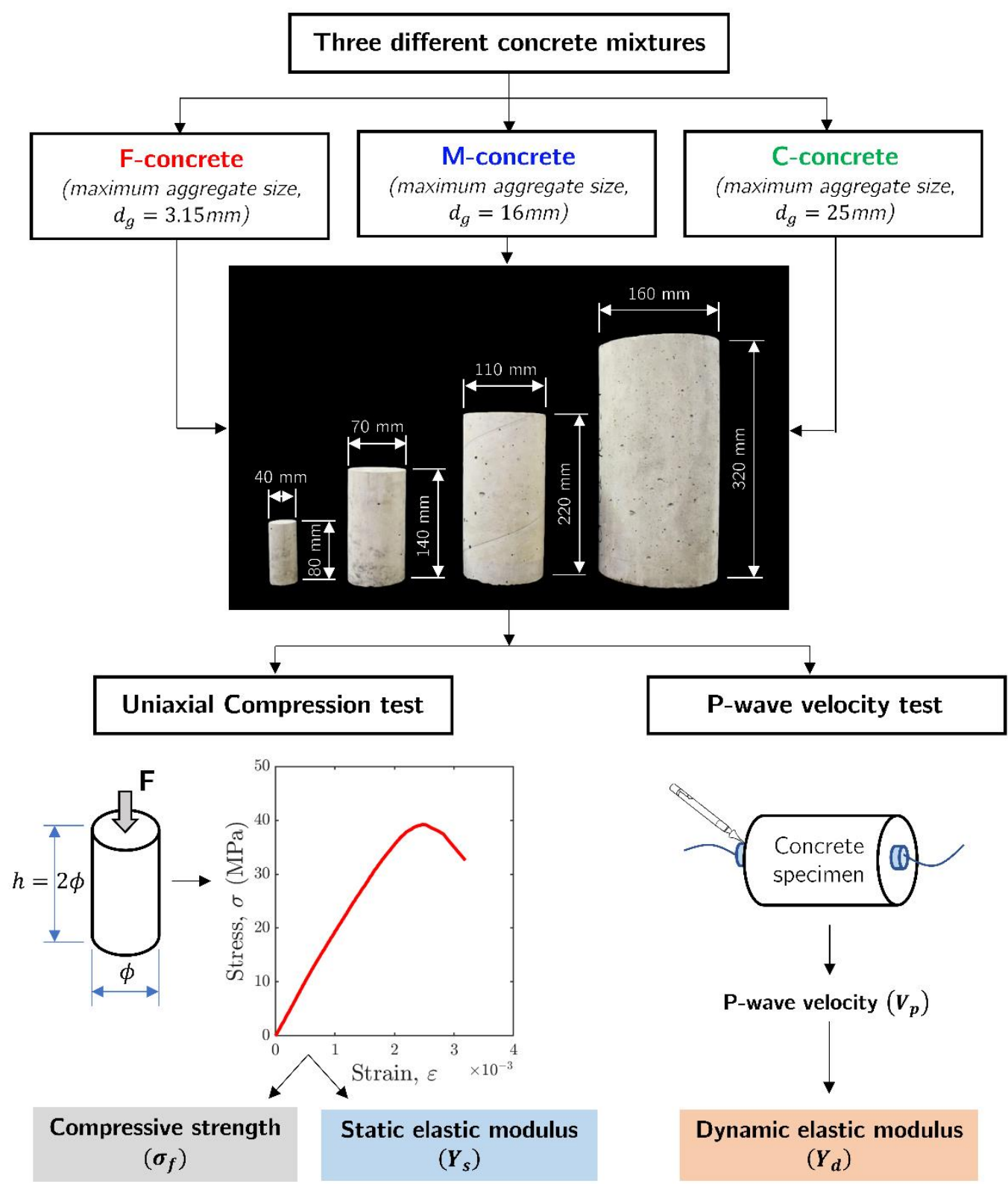

Dynamic elastic modulus $\left(Y_{d}\right)$

Fig. 1. Experimental program 


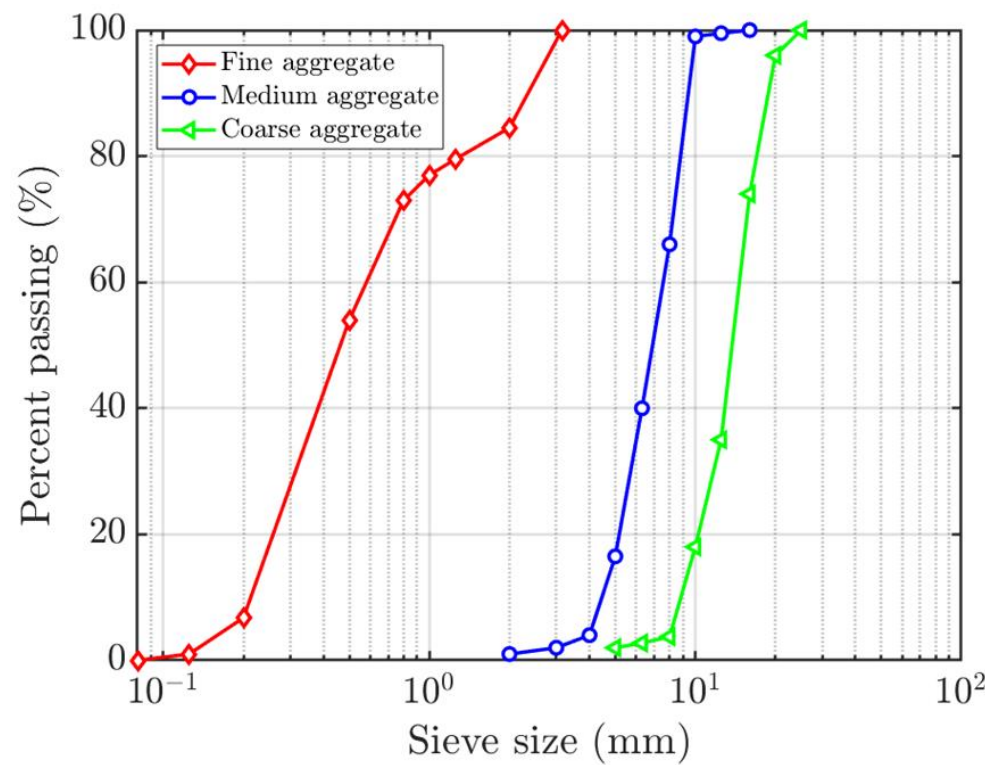

(a)

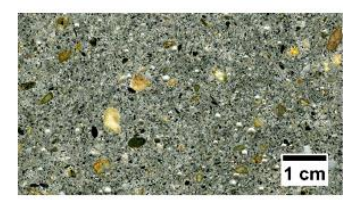

F-Concrete

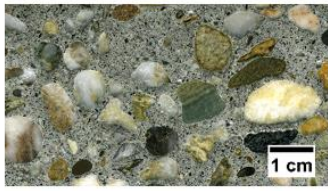

M-Concrete

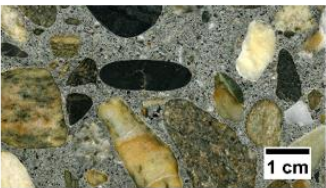

C-Concrete

(b)

Fig. 2. Three different concrete mixtures used for experimental investigations: (a) Size distribution of aggregates; (b) Cross sections of three different concrete groups.
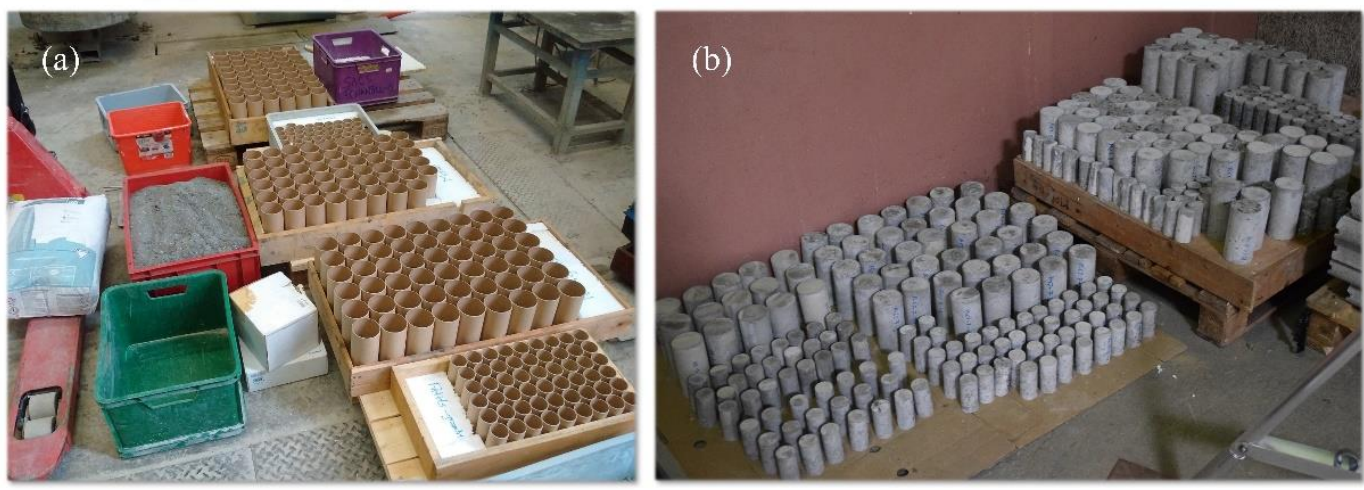

Fig. 3. Different steps of fabrication of the concrete specimens. (a) Raw constituent materials and cylindrical cardboard molds with different sizes used for casting concrete samples; (b) Concrete samples left exposed to atmosphere in the laboratory after the curing period in a water basin. 


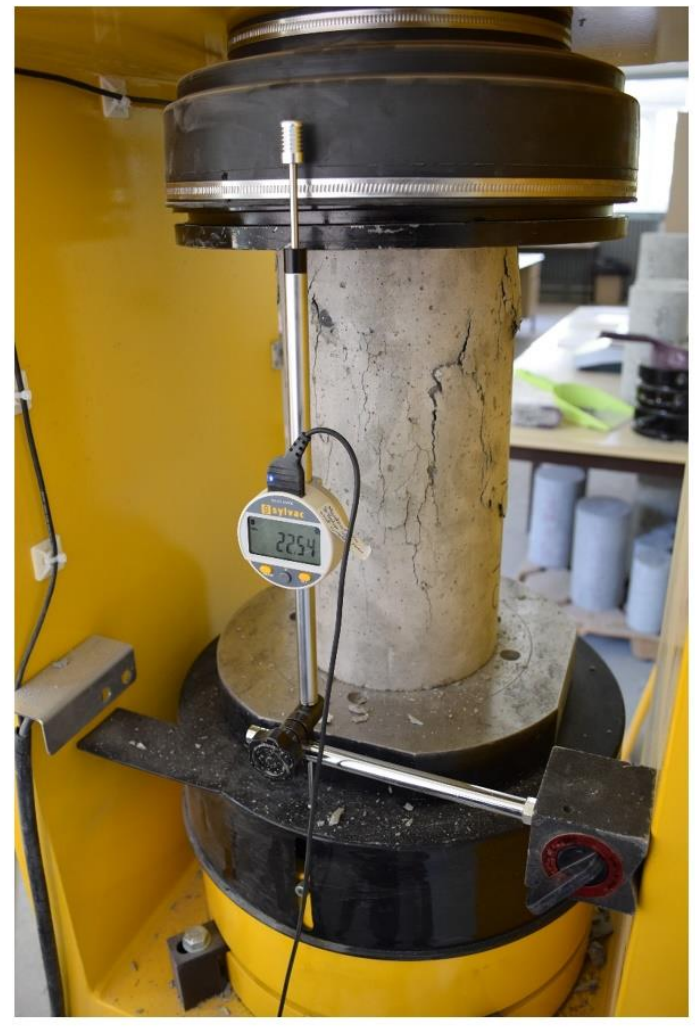

(a)

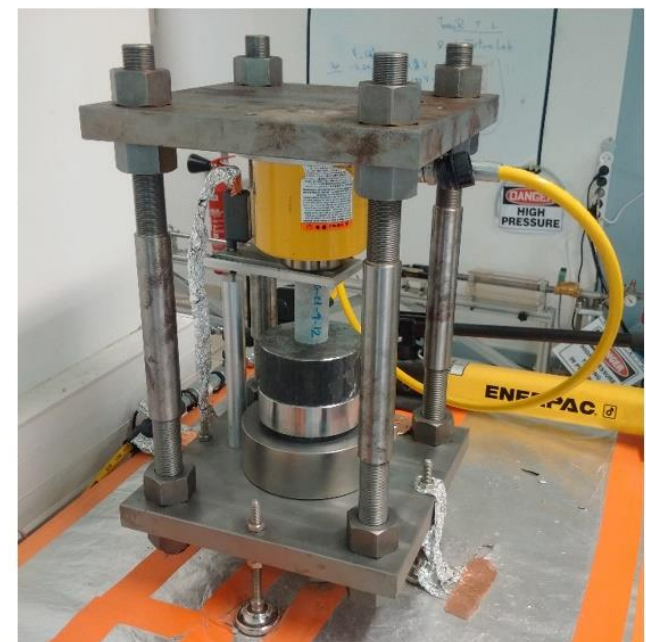

(b)

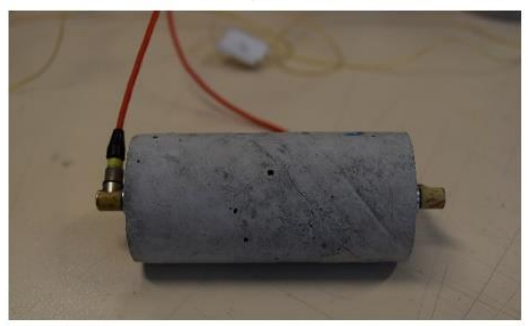

(c)

Fig. 4. Testing setup for: uniaxial compression tests ((a)-Compression machine A and (b)Compression machine B) and (c) P-wave velocity measurements. 

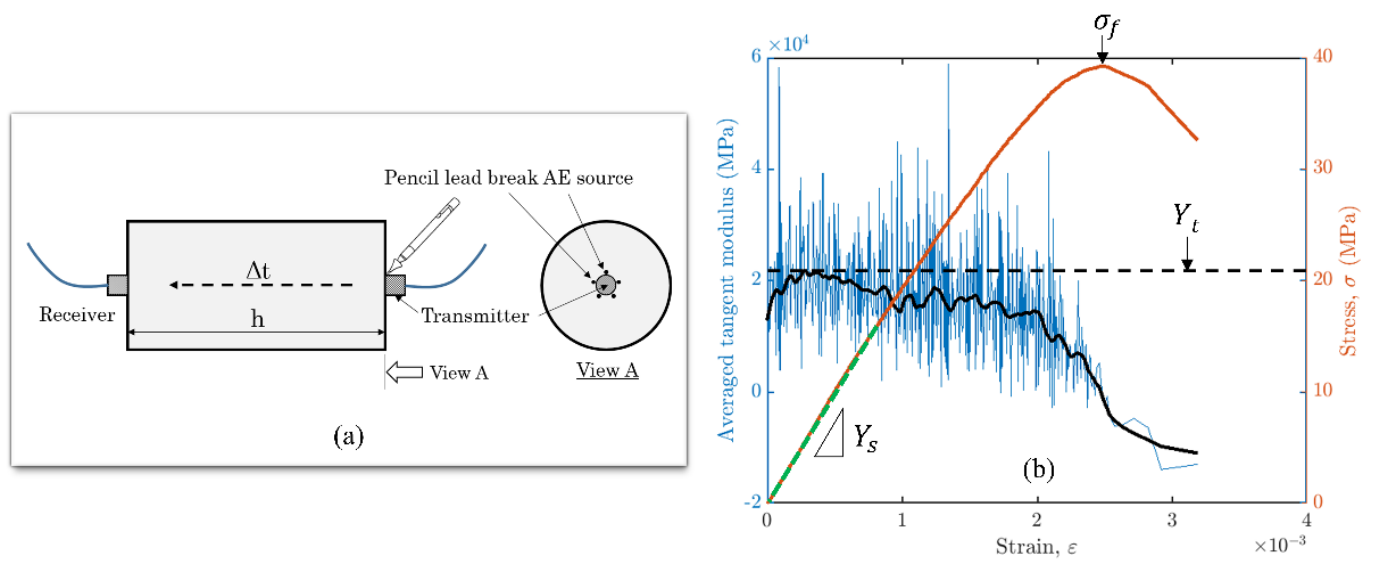

Fig. 5. Determination methods for the elastic moduli of concrete: (a) Testing setup of the acoustic pulse velocity measurement for evaluating the dynamic elastic modulus of a concrete sample; (b) Illustration of the methods of estimation of the tangent elastic modulus $\left(Y_{t}\right)$, where the red curve is the stress-strain curve, the blue curve is the $5 \mathrm{~Hz}$ differentiated stress-strain curve $(d \sigma / d \varepsilon)$ and the solid black curve is the 40-points moving average of the blue curve; and of the secant elastic modulus $\left(Y_{s}\right)$ which is calculated by the slope of a line (dashed green line) drawn from the origin to $40 \%$ of the peak stress $\sigma_{f}$. 

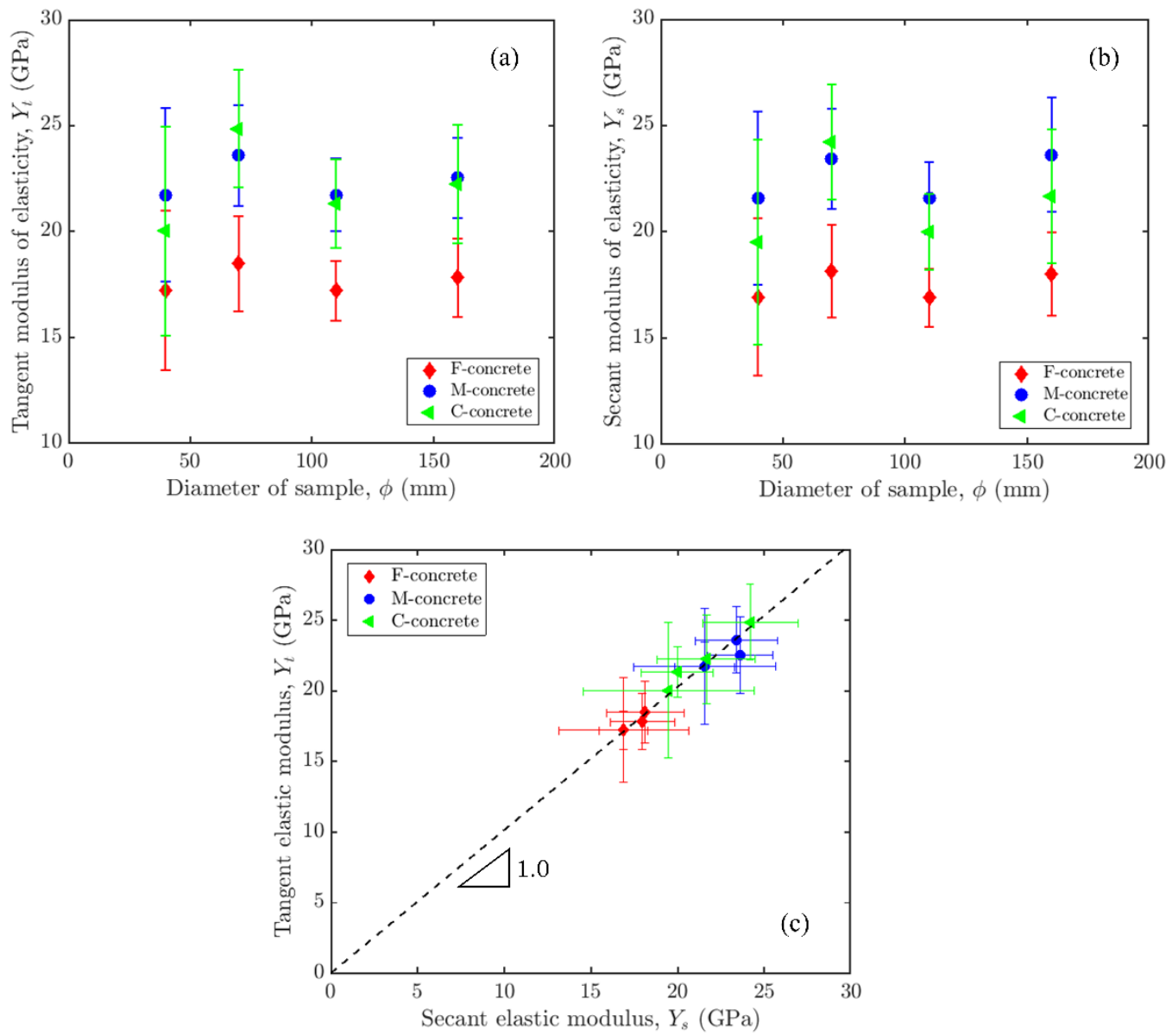

Fig. 6. The values of static elastic moduli for all concrete samples: (a) Tangent modulus, $Y_{t}$; (b) Secant modulus, $Y_{s}$; and (c) The relationship between the secant modulus, $Y_{s}$, and tangent modulus, $Y_{t}$. 

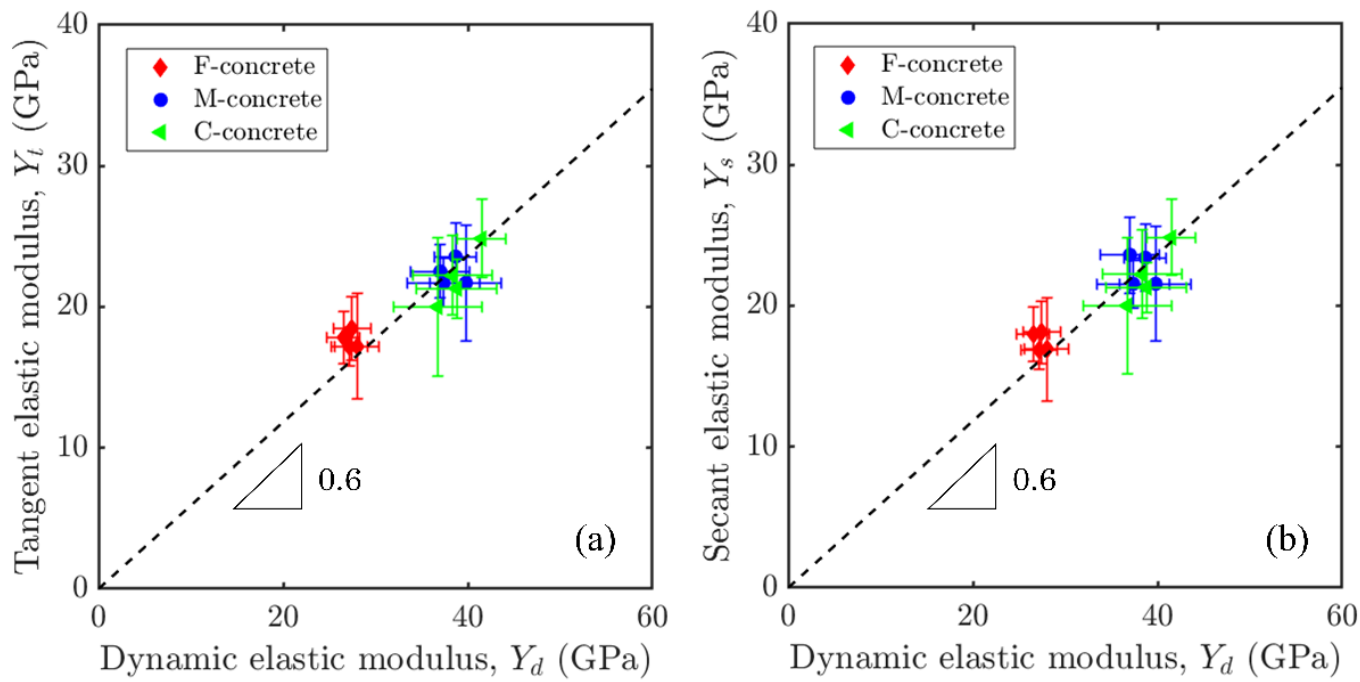

Fig. 7. The relationship between static and dynamic elastic moduli of concrete. (a) $Y_{d}$ vs. $Y_{t}$; and (b) $Y_{d}$ vs. $Y_{t}$. 

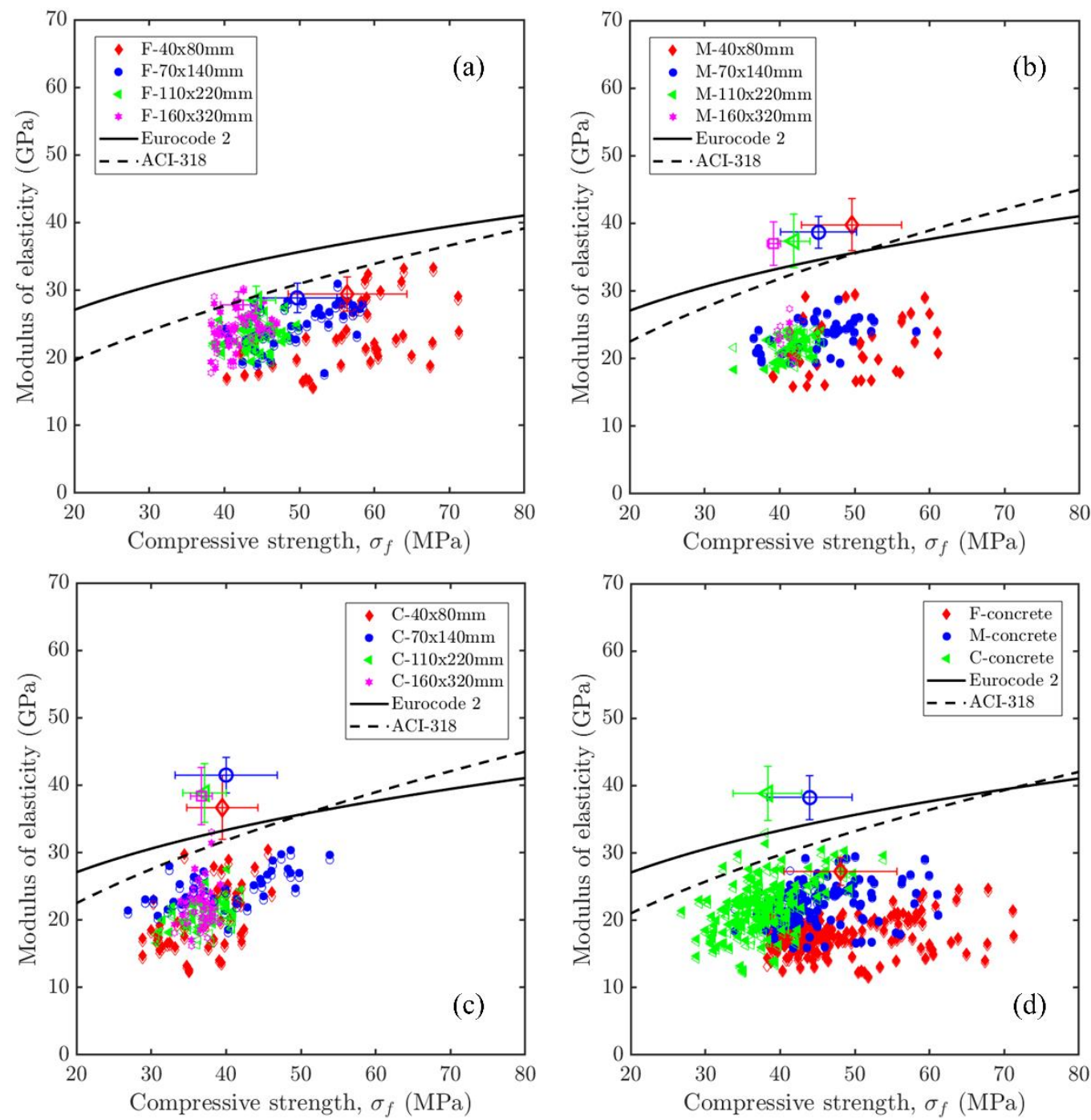

Fig. 8. Relationships between the compressive strength and the elastic modulus of concrete samples: (a) for F-concrete; (b) for M-concrete; (c) for C-concrete and (d) for all concrete samples. Closed symbols are the tangent moduli $\left(Y_{t}\right)$, open symbols are the secant moduli and unfilled symbols with error bars are the dynamic elastic moduli $\left(Y_{d}\right)$. 


\section{Tables}

Table 1. Empirical relations of static Young's modulus with compressive strength

\begin{tabular}{|c|c|c|}
\hline References & $\begin{array}{r}\text { Expression for static Young's } \\
\text { modulus, } Y_{s}(\mathrm{MPa})\end{array}$ & $\begin{array}{r}\text { Range of concrete } \\
\text { strength }\end{array}$ \\
\hline Ahmad and Shah, 1985 [75] & $Y_{S}=\rho^{2.5}\left(f_{c}^{\prime}\right)^{0.325}$ & $f_{c}^{\prime}<84 \mathrm{MPa}$ \\
\hline Kakizaki et al., $1992[5,76]$ & $Y_{s}=3.65\left(f_{c}^{\prime}\right)^{0.5}$ & $80 \mathrm{MPa}<f_{c}^{\prime}<140 \mathrm{MPa}$ \\
\hline CEB-FIB Mode code, 1993 [9] & ${ }^{*} Y_{S}=21500 \alpha_{E}\left(\frac{f_{c k}}{10}\right)^{1 / 3}$ & $f_{c k} \leq 80 \mathrm{MPa}$ \\
\hline Iravani, 1996 [77] & ${ }^{* * *} Y_{s}=4700 C_{c a}\left(f_{c}^{\prime}\right)^{0.5}$ & $55 \mathrm{MPa}<f_{c}^{\prime}<125 \mathrm{MPa}$ \\
\hline Malaikah, 2005 [78] & $Y_{s}=2090\left(f_{c}^{\prime}\right)^{0.5}+22680$ & $45 \mathrm{MPa}<f_{c}^{\prime}<90 \mathrm{MPa}$ \\
\hline Noguchi et al., 2009 [6] & ${ }^{* * *} Y_{s}=k_{1} k_{2} \times 1.486 \times 10^{-3}\left(f_{c}^{\prime}\right)^{1 / 3} \rho^{2}$ & $40 \mathrm{MPa}<f_{c}^{\prime}<160 \mathrm{MPa}$ \\
\hline \multicolumn{3}{|c|}{$\begin{array}{l}\text { Notes: } f_{c}^{\prime} \text { is the specified compressive strength in } \mathrm{MPa}, \rho \text { is the density in } \mathrm{kg} / \mathrm{m}^{3}, f_{c k} \text { is the characteristic } \\
\text { compressive strength in MPa. } \\
{ }^{*} \alpha_{E} \text { is a constant that depends on the type of aggregates. } \\
{ }^{* *} C_{c a} \text { is a coefficient related to the type of aggregates. } \\
{ }^{* * * *} k_{1}, k_{2} \text { are the correction factor corresponding to coarse aggregates and mineral admixtures, respective }\end{array}$} \\
\hline
\end{tabular}

Table 2. Empirical relations of dynamic Young's modulus with compressive strength

\begin{tabular}{|c|c|c|c|}
\hline References & $\begin{array}{l}\text { Expression for dynamic } \\
\text { ung's modulus, } Y_{d}(\mathrm{GPa})\end{array}$ & Type of concrete & NDT method \\
\hline Lee et al., 1997 [36] & ${ }^{*} Y_{d}=a \cdot\left(f_{c}^{\prime}\right)^{b}$ & $\begin{array}{r}\text { Normal weight } \\
\text { concrete }\end{array}$ & Resonant frequency \\
\hline Malhotra et al., 2004 [39] & ${ }^{* *} Y_{d}=8.67 \times 10^{6} \frac{f_{c}^{\prime}}{f_{c}^{\prime}+1550}$ & $\begin{array}{r}\text { Normal weight } \\
\text { concrete }\end{array}$ & Resonant frequency \\
\hline Zhou et al., 2015 [25] & ${ }^{8} Y_{d}=a f_{c}^{0.295}+b$ & $\begin{array}{r}\text { Normal weight } \\
\text { concrete }\end{array}$ & Resonant frequency \\
\hline Jurowski et al., 2018 [24] & ${ }^{\S} Y_{d}=\frac{43 . \rho^{1.5} \cdot 10^{-6}}{1.5 \gamma}\left(f_{c}^{\prime}\right)^{0.5}$ & $\begin{array}{l}\text { Normal and High } \\
\text { strength concrete }\end{array}$ & Resonant frequency \\
\hline Kumar et al., 2019 [9] & $Y_{d}=0.4079\left(f_{c k}\right)^{1.2557}$ & $\begin{array}{r}\text { Self-Compacting } \\
\text { Concrete (SCC) }\end{array}$ & UPV \\
\hline \multicolumn{4}{|c|}{$\begin{array}{l}\text { Notes: } 1 \mathrm{psi}=0.00689476 \mathrm{MPa}, f_{c}^{\prime} \text { is the specified compressive strength in } \mathrm{MPa}, \rho \text { is the density in } \mathrm{kg} / \mathrm{m} 3, f_{c k} \text { is the } \\
\text { characteristic compressive strength in MPa. } \\
* a, b \text { are the experimental coefficients which are found by the linear regression of } \ln \left(f_{c}^{\prime}\right) \text { versus } \ln \left(Y_{d}\right) \\
{ }^{* *} Y_{d} \text { is expressed in psi. } 10^{6} \text { and } f_{c}^{\prime} \text { is measured by psi. } \\
{ }^{\S} a \text { is the coefficient related to the volume content of aggregate and maximum coarse aggregate size; and } b \text { is } \\
\text { coefficient influenced by the volume content of aggregate, maximum coarse aggregate size and water-to-cement ratio. } \\
\S \S \gamma \text { is the volume content of aggregate in the concrete mix. } \\
\text { NDT: Non-Destructive Testing } \\
\text { UPV: Ultra-sonic Pulse Velocity }\end{array}$} \\
\hline
\end{tabular}


Table 3. Empirical relationships between the static $\left(Y_{s}\right)$ and dynamic $\left(Y_{d}\right)$ elastic moduli of concrete

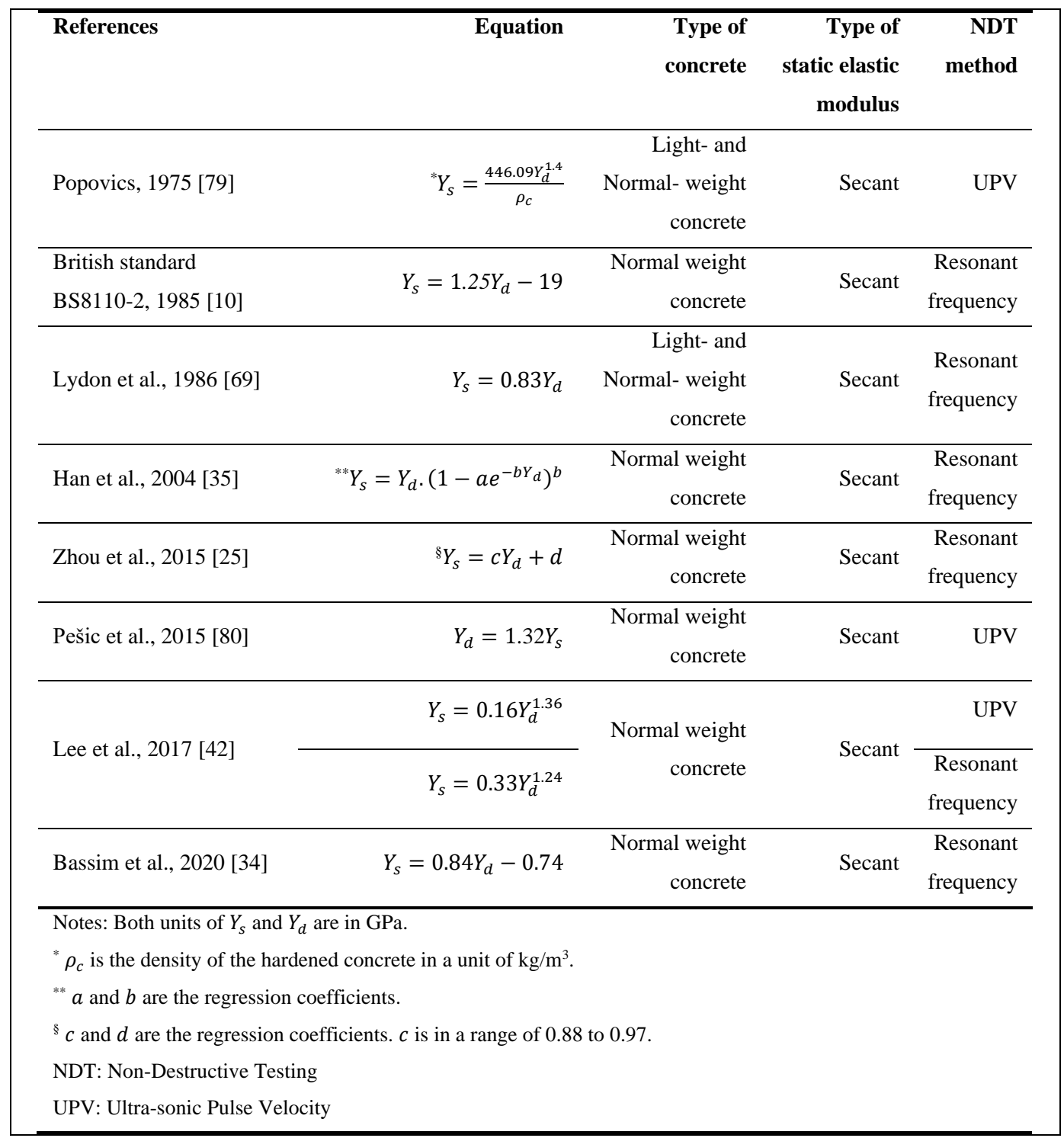

Table 4. Mix proportions for the three concrete groups.

\begin{tabular}{|lrrrrrrrr|}
\hline $\begin{array}{l}\text { Concrete } \\
\text { group }\end{array}$ & $\begin{array}{r}\text { Water } \\
\left(\mathbf{k g} / \mathbf{m}^{\mathbf{3}}\right)\end{array}$ & $\begin{array}{r}\text { Cement } \\
\left(\mathbf{k g} / \mathbf{m}^{\mathbf{3}}\right)\end{array}$ & $\mathbf{W} / \mathbf{C}$ & $\begin{array}{r}\text { Sand } \\
\left(\mathbf{k g} / \mathbf{m}^{\mathbf{3}}\right)\end{array}$ & $\begin{array}{r}\text { Medium } \\
\text { aggregate } \\
\left(\mathbf{k g} / \mathbf{m}^{\mathbf{3}}\right)\end{array}$ & $\begin{array}{r}\text { Coarse } \\
\text { aggregate } \\
\left(\mathbf{k g} / \mathbf{m}^{\mathbf{3}}\right)\end{array}$ & $\begin{array}{r}\text { Maximum } \\
\text { aggregate } \\
\text { size }(\mathbf{m m})\end{array}$ & $\begin{array}{r}\text { Finesse } \\
\text { modulus }\end{array}$ \\
\hline $\mathrm{F}$ & 225 & 450 & 0.50 & 1350 & 0 & 0 & 3.15 & 3.24 \\
$\mathrm{M}$ & 195 & 335 & 0.58 & 800 & 1065 & 0 & 16 & 6.95 \\
$\mathrm{C}$ & 195 & 335 & 0.58 & 800 & 0 & 1065 & 25 & 9.21 \\
\hline
\end{tabular}


Table 5. Density, moisture content, P-wave velocity, static and dynamic elastic moduli of different sample sizes and different concrete groups.

\begin{tabular}{|c|c|c|c|c|c|c|c|c|c|c|c|c|c|}
\hline \multirow[t]{2}{*}{$\begin{array}{l}\text { Concrete } \\
\text { group }\end{array}$} & \multirow[t]{2}{*}{$\begin{array}{l}\text { Sample size, } \\
\phi \times h \\
(\mathrm{~mm} \times \mathrm{mm})\end{array}$} & \multicolumn{2}{|c|}{$\begin{array}{r}\text { Density, } \rho \\
\left(\mathrm{kg} / \mathrm{m}^{3}\right)\end{array}$} & \multicolumn{2}{|c|}{$\begin{array}{r}\text { Moisture } \\
\text { content, } w_{c} \\
(\%)\end{array}$} & $\begin{array}{r}\mathrm{Ta} \\
\text { modu }\end{array}$ & $\begin{array}{l}\text { gent } \\
\text { s, } Y_{t} \\
\text { SPa) }\end{array}$ & modu & $\begin{array}{l}\text { cant } \\
Y_{s} \\
\text { Pa) }\end{array}$ & \multicolumn{2}{|c|}{$\begin{array}{r}\text { P-wave } \\
\text { velocity, } V_{p} \\
(\mathrm{~m} / \mathrm{s})\end{array}$} & \multicolumn{2}{|c|}{$\begin{array}{r}\text { Dynamic } \\
\text { elastic } \\
\text { modulus, } Y_{d} \\
(G P a)\end{array}$} \\
\hline & & Mean & SD & Mean & SD & Mean & SD & Mean & SD & Mean & SD & Mean & SD \\
\hline \multirow{4}{*}{$F$} & $40 \times 80$ & 2204.1 & 20.7 & 5.4 & 0.5 & 17.2 & 3.8 & 16.9 & 3.7 & 3798.0 & 164.5 & 28.0 & 2.4 \\
\hline & $70 \times 140$ & 2201.1 & 11.0 & 5.4 & 0.4 & 18.5 & 2.2 & 18.1 & 2.2 & 3808.1 & 142.6 & 27.4 & 2.0 \\
\hline & $110 \times 220$ & 2177.7 & 25.0 & 5.2 & 0.5 & 17.2 & 1.4 & 16.9 & 1.4 & 3823.7 & 121.7 & 27.2 & 1.8 \\
\hline & $160 \times 320$ & 2153.1 & 25.3 & 5.0 & 0.2 & 17.8 & 1.9 & 18.0 & 2.0 & 3782.4 & 135.5 & 26.5 & 1.8 \\
\hline \multirow{4}{*}{ M } & $40 \times 80$ & 2415.3 & 16.5 & 3.4 & 0.3 & 21.7 & 4.1 & 21.6 & 4.1 & 4343.9 & 211.2 & 39.8 & 3.9 \\
\hline & $70 \times 140$ & 2397.4 & 11.4 & 3.4 & 0.3 & 23.6 & 2.4 & 23.4 & 2.4 & 4337.0 & 134.4 & 38.7 & 2.3 \\
\hline & $110 \times 220$ & 2386.3 & 18.6 & 3.0 & 0.1 & 21.7 & 1.7 & 21.6 & 1.7 & 4268.6 & 225.7 & 37.4 & 4.0 \\
\hline & $160 \times 320$ & 2366.4 & 12.4 & 2.9 & 0.3 & 22.5 & 1.9 & 23.6 & 2.7 & 4283.0 & 187.9 & 37.0 & 3.2 \\
\hline \multirow{4}{*}{$\mathrm{C}$} & $40 \times 80$ & 2415.1 & 25.2 & 3.4 & 0.4 & 20.0 & 4.9 & 19.5 & 4.8 & 4168.7 & 293.9 & 36.0 & 4.7 \\
\hline & $70 \times 140$ & 2421.6 & 11.7 & 3.4 & 0.4 & 24.8 & 2.8 & 24.2 & 2.7 & 4476.2 & 166.0 & 41.5 & 2.7 \\
\hline & $110 \times 220$ & 2393.9 & 17.6 & 3.0 & 0.2 & 21.3 & 2.1 & 20.0 & 1.8 & 4359.4 & 262.4 & 38.8 & 4.4 \\
\hline & $160 \times 320$ & 2384.6 & 18.0 & 3.1 & 0.2 & 22.2 & 2.8 & 21.7 & 3.1 & 4365.5 & 252.3 & 38.3 & 4.3 \\
\hline
\end{tabular}


Table 6. Compressive strength $\left(\sigma_{f}\right)$ and its correlation coefficient with the static moduli $\left(Y_{t}\right.$ and $\left.Y_{s}\right)$ for different concrete samples.

\begin{tabular}{|c|c|c|c|c|c|}
\hline \multirow{2}{*}{$\begin{array}{l}\text { Concrete } \\
\text { group }\end{array}$} & \multirow{2}{*}{$\begin{array}{l}\text { Sample sizes, } \\
\phi \times h(\mathbf{m m} \times \mathbf{m m})\end{array}$} & \multicolumn{2}{|c|}{$\begin{array}{r}\text { Compressive strength, } \\
\sigma_{f}(\mathrm{MPa})\end{array}$} & \multirow[t]{2}{*}{$\sigma_{f}$ vs. $Y_{t}$} & \multirow[t]{2}{*}{$\sigma_{f}$ vs. $Y_{s}$} \\
\hline & & Mean & SD & & \\
\hline \multirow{4}{*}{$\mathrm{F}$} & $40 \times 80$ & 56.4 & 7.9 & 0.42 & 0.42 \\
\hline & $70 \times 140$ & 49.7 & 5.3 & 0.43 & 0.43 \\
\hline & $110 \times 220$ & 44.3 & 2.4 & 0.19 & 0.09 \\
\hline & $160 \times 320$ & 41.9 & 2.4 & 0.27 & 0.21 \\
\hline \multirow{4}{*}{ M } & $40 \times 80$ & 49.6 & 6.2 & 0.21 & 0.21 \\
\hline & $70 \times 140$ & 45.2 & 4.2 & 0.38 & 0.38 \\
\hline & $110 \times 220$ & 41.9 & 1.9 & 0.41 & 0.20 \\
\hline & $160 \times 320$ & 39.2 & 1.8 & -0.06 & -0.36 \\
\hline \multirow{4}{*}{$\mathrm{C}$} & $40 \times 80$ & 39.5 & 4.6 & 0.40 & 0.40 \\
\hline & $70 \times 140$ & 40.0 & 6.3 & 0.48 & 0.48 \\
\hline & $110 \times 220$ & 37.1 & 2.7 & 0.45 & 0.15 \\
\hline & $160 \times 320$ & 36.7 & 1.4 & 0.12 & 0.03 \\
\hline
\end{tabular}

